American Journal of Agricultural and Biological Sciences 2 (3): 149-152, 2007

ISSN 1557-4989

(C) 2007 Science Publications

\title{
An in vitro Permeation of Phyllanthus amarus Extract Through Human and Shed Snake Skins
}

\author{
${ }^{1}$ Aroonsri Priprem, ${ }^{1}$ S. Radapong, ${ }^{1}$ S. Preeprame, ${ }^{1} \mathrm{P}$. Chitropas, ${ }^{1}$ T. Rittirod, ${ }^{2} \mathrm{P}$. Theerakulpisut
} and ${ }^{2} \mathrm{P}$. Chantranothai

${ }^{1}$ Faculty of Pharmaceutical Sciences, Khon Kaen University, Muang, Khon Kaen 40002, Thailand ${ }^{2}$ Department of Biology, Faculty of Science, Khon Kaen University, Muang, Khon Kaen 40002, Thailand

\begin{abstract}
An in vitro permeation of a hydroalcoholic extract of Phyllanthus amarus (PaE) was investigated using excised human epidermis and shed king cobra skin as the barrier membranes. Donor and receptor compartments of diffusion cells were $\mathrm{pH}$-controlled to simulate the permeation environment of the human skin. The PaE was analyzed by using normal-phase densitometric TLC detected at $\lambda 280 \mathrm{~nm}$ and toluene:ethyl acetate (17:3) as the mobile phase. There were four major components observed in the saturated solution of the donor at $\mathrm{pH} 5.5$. Over $24 \mathrm{~h}$, only one component, possibly phyllanthin, was found in the receptor solution after permeation across the human epidermis, while two components, possibly phyllanthin and an another unknown permeated, permeated through shed snake skin. When compared to the saturated donor concentration, phyllanthin gave permeation fluxes of $0.04 \pm 0.01$ and $0.12 \pm 0.02 \% \cdot \mathrm{cm}^{-2} \cdot \mathrm{h}^{-1}$ through the human and shed snake skins, respectively. It seems that only certain component(s) of the $P$. amarus extract could permeate through the skins, and by comparison, at a slower rate across the human skin than shed snake skin.
\end{abstract}

Key words: Phyllanthus amarus, human skin, shed snake skin, in vitro permeation

\section{INTRODUCTION}

Dermatological applications of herbal extracts for pharmaceutical and cosmetic purposes may have delivered some components which were not well documented. In vitro permeation studies by using various designs of diffusion cells have been one of the methods used to simulate percutaneous absorption of drugs or other compounds ${ }^{[1]}$. In vitro permeation studies of herbal extracts could be a supportive part for development of rationale use of phytotherapy. Phyllanthus amarus Schum \& Thonn. (P. amarus), family Euphorbiaceae, was selected for study due to its traditional claims for treatment of skin diseases and recent reports on its activities as an antiinflammatory $^{[2,3]}$, antibacterial ${ }^{[4]}$, antifungus particularly dermatophytic fungi ${ }^{[5]}$ and potent antioxidant properties ${ }^{[6]}$. Active components of $P$. amarus such as phyllanthin and hypophyllanthin have been isolated and identified $^{[7,8]}$. Different species of Phyllanthus could be similar in morphology but different in pharmacological activities to P.amarus ${ }^{[2,8]}$, it is necessary to confirm the plants being used.

The skin plays a vital role in controlling the passage of substances. The permeation of any compounds through the skin involves physicochemical characteristics of the compounds, the vehicle and the barrier membrane ${ }^{[9,10]}$.

Passage of a dissolved compound across the human skin generally occurs from an outer skin $\mathrm{pH}$ of about 5 through various layers, and if possible, to a sink condition with a physiological $\mathrm{pH}$ of 7.4. Human skin is not as readily available as the waste material like shed snake skin, and both have been shown to give comparable in vitro permeation ${ }^{[9,10,11,12]}$. This includes king cobras (Ophiophagus hannah) ${ }^{[12]}$ which shed large pieces of skin readily usable for several experiments.

This study employed the human epidermis and shed snake skin as the barrier membranes and controlled the $\mathrm{pH}$, which is likely to be one of the vital factors influencing the permeation of a hydroalcoholic extract of P.amarus (PaE). The permeation profile studied by this type of herbal extract could provide a vital information for further product development.

\section{MATERIALS AND METHODS}

Chemicals: Chemicals used include trichloromethane (Mallinckrodt Chemical Inc., U.S.A.), methanol (Fisher Scientific, U.K.), toluene (Merck, Sweden), glacial 
acetic acid (J.T. Baker, U.S.A.), ethyl acetate (Lab Scan Analytical Sciences, Ireland), agarose gel (ISC Bioexpress, U.S.A.) and ethidium bromide (Fluka Chemika, U.S.A.). All solvents were analytical grade. Thin layer chromatography (TLC) plates were silica gel 60 $\mathrm{F}_{254}(20 \times 20 \times 0.0025 \mathrm{~cm}$, Merck, Germany $)$.

Preparation of the human epidermis and shed snake skin: Fresh, surgically excised samples of human skin were obtained directly after breast plastic surgery with informed consent following ethical approval. Shed king cobras skin were kindly gifted and collected freshly from the Khok Sanga King Cobra Club, Khon Kaen, Thailand. These were kept at $-21^{\circ} \mathrm{C}$ until use. The human epidermis was separated as previously described $^{15}$ while the dorsal scales of the shed snake skin were used as received.

Collection of plant: Whole plants of $P$. amarus were collected from Khon Kaen province, Thailand, during the rainy season (May-August) year 2005 and 2006. The identity of the plant was certified by one of us (P.C.) and the plant specimen was kept in the herbarium collection of Faculty of Pharmaceutical Science (collection number PSH-KKU-05/AP01, PSH-KKU-06/AP01).

DNA identification of $P$. amarus by sequence characterized amplified region (SCAR): Fresh leaves of $P$. amarus were used for genomic DNA extraction following a previously described method ${ }^{16}$. The PCR amplification and reactions were performed in a thermocycler (PCR Sprint, U.S.A.) and the products were electrophoretically separated in $1.2 \%(\mathrm{w} / \mathrm{v})$ agarose gel and staining-visualized with ethidium bromide. The RAPD fingerprint pattern resulting from amplification was compared with the SCAR primers of $P$. amarus collection at the Department of Biology, Khon Kaen University.

Phyllanthus extract (PaE): Dried powder of whole plants of $P$. amarus was macerated in $50 \%$ ethanol $(1: 6$, $\mathrm{v} / \mathrm{v})$ at $25 \pm 2^{\circ} \mathrm{C}$ for 7 days. The supernatant was concentrated by reduced pressure evaporator (Tokyo Rikakikai Co. Ltd., Japan), freeze-dried (FTS systems, U.S.A.) and pulverized. Average yields of $\mathrm{PaE}$ were $2.4 \%$ by fresh weight or $7.9 \%$ by dried weight.

Permeation studies: Side-by-side diffusion cells (area of $0.694 \mathrm{~cm}^{2}$, Crown Glass Company, U.S.A.) with controlled circulation of solutions at $600 \mathrm{rpm}$ and temperature at $32 \pm 1^{\circ} \mathrm{C}$ were employed. Donor compartments were filled with $\mathrm{PaE}$ saturated in citrate phosphate buffer at $\mathrm{pH} 5.6$ and receptor compartments with phosphate buffer at $\mathrm{pH}$ 7.4. Samples were collected from the receptor compartments for analysis and replaced by the same volume of fresh phosphate buffer.

\section{Analysis by normal phase thin layer chromatography (TLC) with densitometer:} Extraction of samples was conducted by using several portions of chloroform until completion. The whole portions of the chloroform extract were collected, mixed and dried under nitrogen gas, then dissolved with $0.1 \mathrm{ml}$ methanol. $0.02 \mathrm{ml}$ of the methanol extract was taken and spotted on the TLC siliga gel plates. The mobile phase used for eluting the plates was a mixture of toluene: ethyl acetate (17:3). The plates were scanned at a wavelength of $280 \mathrm{~nm}$ using a densitometer TLC Scanner 4 (Camag, Switzerland) linked to WinCATS4 software.

\section{RESULTS AND DISCUSSION}

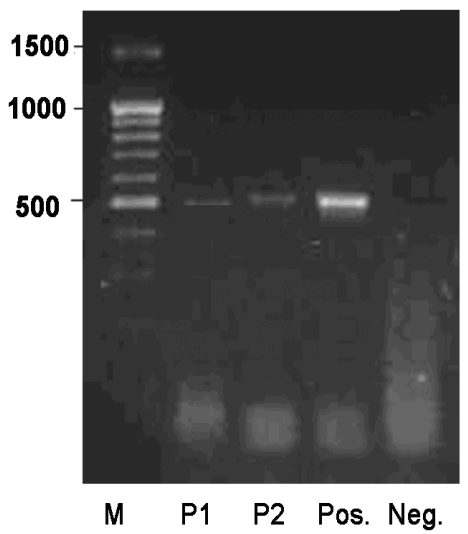

Fig. 1: Amplified DNA bands resulting from PCR amplification of genomic DNA of $P$. amarus collected at two occasions (P1 and $\mathrm{P} 2)$. The PCR reactions were initiated with SCAR primers specific for $P$. amarus. $\mathrm{M}=$ DNA marker, Pos. $=$ DNA of $P$. amarus reference plant, Neg.= negative control without DNA.

Collections of the plants from different occasions, $\mathrm{P} 1$ and P2, gave the same yield of PaE. Taxonomical 
identification of $P$. amarus by an expert was confirmed by genomic DNA, as shown in Figure 1.

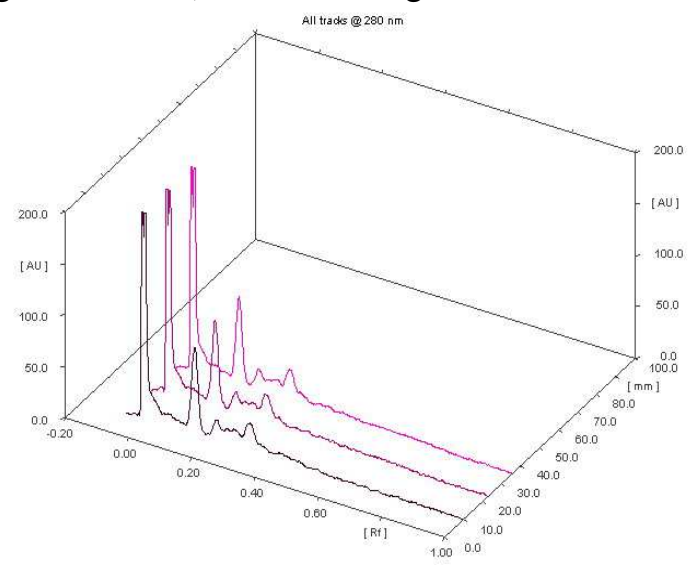

Fig. 2: TLC chromatogram of PaE saturated in the donor solution (1:10 dilution) at 6,12 and $24 \mathrm{~h}$ of permeation study. Analysis conditions: normal phase densitometric TLC; $\mathrm{G}_{60} \mathrm{~F}_{254}$ silica gel plate $(20 \times 10 \mathrm{~cm})$; mobile phase of toluene: ethyl acetate (17:3); and $\lambda 280 \mathrm{~nm}$.

PCR amplification of DNA of both collections (P1 and $\mathrm{P} 2$ ) using $P$. amarus - specific primers gave rise to a specific band of approximately $500 \mathrm{bp}$. The extraction process gave reproducible yields of a fine, hygroscopic and light-brown powder. $\mathrm{PaE}$ was hydrophilic, i.e. soluble in water, ethanol and insoluble in chloroform and $\mathrm{n}$-hexane, and hygroscopic.

The TLC chromatograms of PaE saturated in the donor solution showed 2-3 resolution color bands on silica plate at $\mathrm{R}_{f}$ value about $0.1-0.5$. The extract showed a good resolution of peak no. 1 and 2 at average $\mathrm{R}_{f}$ of 0.21 and 0.28 , as shown in Figure 2, which resembles the peaks of phyllanthin [8] and an unknown. The receptor solutions using shed snake skin as the barrier at 6,12 and $24 \mathrm{~h}$ could separate $3-4$ peaks (as shown in Figure 3).

At sink conditions, the permeation of phyllanthin linearly increased with time from donor solution with the skin $\mathrm{pH}$ of 5.5 to receptor solution at $\mathrm{pH} 7.4$. An attempt to estimate the permeation rates of peak no. 1 (at $\mathrm{R}_{f}$ 0.21) during 6-24 h, analyzed by linear regression, were $0.04 \pm 0.01$ and $0.12 \pm 0.02 \% \cdot \mathrm{cm}^{-2} \cdot \mathrm{h}^{-1}$ through the human epidermis and shed snake skin, respectively, with correlation coefficient of more than 0.999. Another unknown substance as shown by a presence of peak no. 2 at $\mathrm{R}_{f} 0.28$ permeated when using shed snake skin at a slower rate of $0.006 \% \cdot \mathrm{cm}^{-2} \cdot \mathrm{h}^{-1}$.

It is concluded that phyllanthin, one of the major components of P.amarus, could permeate through the barrier structure of both human and shed snake skins. Further study is required to qualitatively identify each component and investigate the competitive permeation profile of the mixtures which are usually found when using any herbal extracts.

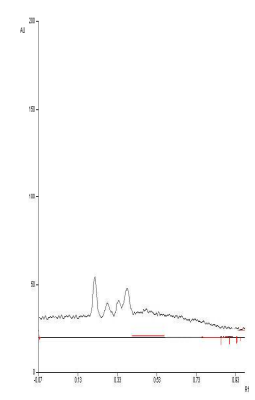

(a)

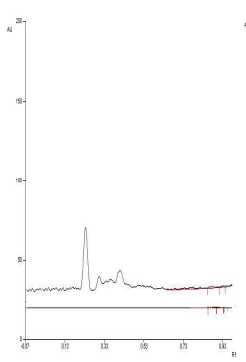

(d)

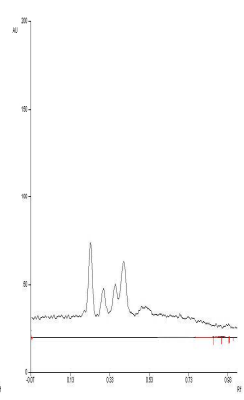

(b) (c)

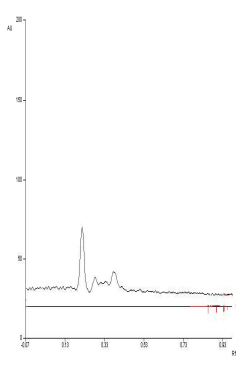

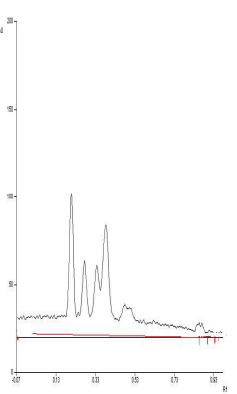

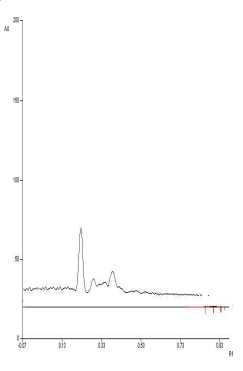

(f)

Fig. 3: TLC chromatograms of PaE permeated into the receptor solution (phosphate buffer $\mathrm{pH}$ 7.4) through shed snake skin $(\mathrm{a}-\mathrm{c})$ and the human epidermis $(\mathrm{d}-\mathrm{f})$ from the donor solution (buffer at pH 5.5) at (a) $6 \mathrm{~h}$, (b) $12 \mathrm{~h}$ and (c) 24 $\mathrm{h}$; at $32 \pm 1^{\circ} \mathrm{C}$. Analysis conditions: normalphase densitometric TLC: $\mathrm{G}_{60} \mathrm{~F}_{254}$ silica gel plate $(20 \times 10 \mathrm{~cm}) ;$ mobile phase of toluene: ethyl acetate (17:3); and $\lambda 280 \mathrm{~nm}$.

\section{CONCLUSION}

Some components of the extract of P.amarus were shown to permeate through the scales of the shed skin of king cobras and the human epidermis. The permeation could be a passive transport mechanism influenced by the physicochemical properties of the compounds involved. The human skin gave a slower 
rate of permeation than the scales of shed snake skin which could be the result of differences in lipid compositions. This, however, suggests a potential development of a topical use of $\mathrm{PaE}$, provided that the activities of the substance(s) were proved.

\section{ACKNOWLEDGMENTS}

The National Science and Technology Development Agency (Code No. MT-B-47-BMD-12-097-G) and the National Research Council of Thailand and are thanked for their financial support. Office to support the Royal Innovative Projects at Khon Kaen University, Assist. Prof. Dr. Taweesak Titimetharoj, Faculty of Pharmaceutical Science, Khon Kaen University and Dr. Methin Padungkij, Faculty of Pharmacy, Mahasarakham University, are also thanked for their technical support.

\section{REFERENCES}

1. Magnusson, B.M. and L.-O.D. Koskinen, 2000. In vitro percutaneous penetration of topically applied capsaicin in relation to in vivo sensation responses. Int. J. Pharm., 195: 55-62.

2. Calixto, J.B., Santos, A.R., Cechinel, F.V. and R.A. Yunes, 1998. A review of the plants of the genus Phyllanthus: their chemistry, pharmacology, and therapeutic potential. Med. Res. Rev., 18: 225-258.

3. Kiemer, A.K., Hartung, T., Huber, C. and A.M. Vollmar, 2003. Phyllanthus amarus has anti-inflammatory potential by inhibition of iNOS, COX-2, and cytokines via the NF-kappaB pathway. J. Hepatol., 38: 289-297.

4. Kloucek, P., Polesny, Z., Svobodova, B., Vlkova, E. and L. Kokoska, 2005. Antibacterial screening of some Peruvian medicinal plants used in Calleria District. J. Ethnopharmacol., 99: 309-312.

5. Agrawal, A., Srivastava, S., Srivastava, J.N. and M.M. Srivasava, 2004. Evaluation of inhibitory effect of the plant Phyllanthus amarus against dermatophytic fungi Microsporum gypseum. Biomed. Environ. Sci., 17(3): 359-365.

6. Kumaran, A. and R.J. Karunakaran, 2007. In vitro antioxidant activities of methanol extracts of five Phyllanthus species from India. J. L.W.T., 40(2): 344-352.
7. Dhalwal, K., Biradar, Y. S. and M. Rajani, 2006 High performance thin layer chromatography dencitometric method for simultaneous quantitation of phyllanthin, hypophyllanthin, gallic acid, and ellagic acid in Phyllanthus amarus. J. AOAC Int., 89(3): 619-623.

8. Khatoon, S., Rai, V., Rawat, A.K.S. and S. Mehrotra, 2006. Comparative pharmacognostic studies of three Phyllanthus species. J. Ethnopharmacol., 104: 79-86.

9. B.W., Barry, 2001. Novel mechanisms and devices to enable successful transdermal drug delivery. Eur. J. Pharm. Sci., 14: 101-114. .

10. Schmook, F.P., Meingassner, J.G. and A. Bilich, 2001. Comparison of human skin or epidermis models with human and animal skin in in vitro percutaneous absorption. Int. J. Pharm., 215: 51-56. .

11. Higuchi, T. and L. Kans, 1988. Method for in vitro determination of transdermal absorption. United States Patent., 4771004.

12. Itoh, T., Xia, J., Magavi, R., Nishihata, T. and J.H. Ritting, 1990. Use of shed snake skin as a model membrane for in vitro percutaneous penetration studies: comparison with human skin. Pharm. Res., 7(12): 1042-1047. .

13. Rigg, P.C. and B.W. Barry, 1990. Shed snake skin and hairless mouse skin as model membranes for human during permeation studies. J. Invest. Dermatol., 94: 235-240. .

14. Pongjanyakul, T., Prakongpan, S., Panomsuk, S., Puttipipatkhachorn, S. and A. Priprem, 2002. Shed king cobra skin and cobra skin as model membranes for in-vitro nicotine permeation studies. J. Pharm. Phamacol., 54: 1345-1350. .

15. Akomeah, F., Nazir, T., Martin, G.P. and M.B. Brown, 2004. Effect of heat on the percutaneous absorption and retention of three model penetrants. Eur. J. Pharm. Sci., 21: 337-345. .

16. Doyle, J.J. and J.L. Doyle, 1987. A rapid DNA isolation procedure from small quatities of fresh leaf tissue. Phytochem. Bull., 19: 11-15. . 